\title{
Analysis of Sweetness Components by Harvest Times and Extract Methods in Stevia
}

\author{
Sang Un Kim \\ Department of Agronomy, Gyeongsang National University, Jinju, 52828, Korea \\ Tel : 82-55-772-1877_E-mail: freespace9767@hanmail.net \\ In Seok Um \\ Department of Agronomy, Gyeongsang National University, Jinju, 52828, Korea \\ Tel : 82-55-772-1877Ｅ-mail: oc210712@gmail.net \\ Il Rae Rho (Corresponding author) \\ Department of Agronomy (Institute of Agriculture \& Life Science), Gyeongsang National \\ University, Jinju, 52828, Korea
}

Tel : 82-55-772-1877_ E-mail: irno12@gnu.ac.kr

Received: Jan. 8, 2019

doi:10.5296/jas.v7i1.14166
Accepted: Jan. 28, 2019 Published: Jan. 29, 2019

URL: https://doi.org/10.5296/jas.v7i1.14166

\begin{abstract}
The leaves of Stevia rebaudiana Bertoni have attracted much attention as a source of natural sweeteners. This study was conducted to investigate the natural sweeteners contents and analyze antioxidant materials and activity according to harvest times and extraction methods in stevia.

Stevia leaves were extracted using 5 extraction methods to identify the extraction with high extraction efficiency. Extraction yield was high in the order of hot water extraction (HWE), reflux extraction (RE), high temperature and pressure extraction (HTPE), ultrasonic extraction (UE) and vacuum extraction (VE). The contents of rebaudioside A and stevioside in stevia leaves had the highest in HTPE. Also, the total phenolic and flavonoid contents had the highest in HTPE and VE. Using the HTPE method, the result analyzed that the contents of rebaudioside A and stevioside of stevia leaves harvested between April and October exhibited the tendency to increase gradually between July and October. HTPE is considered to be an appropriate method for extracting stevia leaves. Also, it was confirmed that the stevia leaves of July, September and October, except for the high temperature period of August, had superior in quality and quantity.
\end{abstract}


Keywords: Antioxidant, Extraction efficiency, Stevia rebaudiana Bertoni, Steviol glycoside, Sugar substitute

\section{Introduction}

Currently, obesity and adult diseases as a result of sugar intake have been a consistent problem in Korea (Hwang et al., 2016). Consequently, research on low caloric sweeteners that can substitute sugar has been consistently conducted (Park, 2007; Lee and Kim, 2004; Na et al., 2012). Natural sweeteners as sugar substitutes have many advantages over sugar as a small quantity, but a lot of research is required regarding its application to various foods science it has low preference compared to sugar (Kim and Lee, 2012). Recently, there have been dynamic researches conducted on stevia as natural sweetener substitute for sugar (Esmat et al., 2010).

Stevia (Stevia rebaudiana Bertoni) grows in local highland of an altitude over $1000 \mathrm{~m}$ as in Brazil and Paraquay, belonging to the chrysanthemum family as a perennial herb plant. Sweeteners of stevia were mainly extracted from its leaves with plant height of $40 \sim 60 \mathrm{~cm}$. Sweetener components in stevia are glycosides of the diterpene derivative steviol, consisting mainly of stevioside and rebaudioside $\mathrm{A}$, as well as with the extremely minor components which includes rebaudioside B, C, D, E, steviolbioside and dulcoside A. Steviol glycosides have low calorie and sweetening potentials 200 300 times than sucrose, with low sugariness index. So, it is used for various processed food as natural sweeteners to substitute sugar (Lim and Oh, 2004). Many researchers have reported that stevia may be used not only for its sweetening purposes, but also for its physiologic and therapeutic effect (Park, 2007). Since the substitute of artificial sweeteners with stevia, stevia has been identified by researchers to have numerous efficiency such as antibacterial and anticancer activity (Tomita et al., 1997), anti-diabetic effect (Dyrskog et al., 2005), antioxidant activity (Tadhani et al., 2007, Kim et al., 2009), and anti-obesity and the effect of regulation of blood glucose (Park, 2007; Park et al., 2010).

Stevia extracts were reported to contain steviol glycosides like stvioside and rebaudiosid A, as well as various polyphenol compounds (Kim et al., 2010). From the analyzed result, polyphenolic compound content in various herb plants showed the highest content in stevia (Yamamoto et al., 2001). Also, stevia was more effective for antioxidant activity than those of other abiotic stresses (Choi et al., 2011) and it observed the highest antioxidant activity compared to trolox of strong antioxidant (Tadhani et al., 2007).

Stevia extract method were conducted by some researchers (Lim and Oh, 2004; Kim et al., 2010; Afandi et al., 2013; Periche et al., 2015). Periche et al. (2015) reported that the greatest yield of steviol glycosides was obtained with microwave treatment, but the conventional high temperature method $\left(90^{\circ} \mathrm{C}, 1 \mathrm{~min}\right)$ was the most suitable for antioxidant extraction. In addition, Kim et al. (2010) reported that vacuum extraction was proper for higher antioxidant activity. Afandi et al. (2013) reported that methanol is the best solvent for the extraction of rebaudidoside A. So, there are some troubles related with extract methods, considering components and antioxidant activity. Although there are lots of researches on the efficiency of stevia, researches related to harvest period in stevia and change components by extraction 
method are few. Therefore, this study was conducted to select optimum extraction method based on reported methods and extraction time by measuring the natural sweeteners contents, analyzing antioxidant materials and activity according to harvest times, parts of plant, and extraction methods.

\section{Materials and Methods}

\subsection{Experimental Materials}

Stevia 'Dajung' cultivar was purchased from a local market and was cultivated in a plastic house from May to December. The leaves were harvested from April to October and the stem were only harvested in July and September, which reported the high period in component content of stevia. The extraction method experiments only used leaves harvested on September.

\subsection{Extraction Yield and Methods}

Leaves harvested for experiment on extraction methods were washed and investigated dry weight after drying at room temperature for two weeks. They were ground into fine powder using a mill, and were extracted by 5 methods which are: hot water extraction (HWE), reflux extraction (RE), high temperature and pressure extraction (HTPE), ultrasonic extraction (UE) and vacuum extraction (VE). The extracts were stored at $-20^{\circ} \mathrm{C}$ until analysis and were used to dilute 10 times of distilled water for experiments. Extraction yield was calculated using the formula below. Extraction yield $(\%)=($ weight after lyophilization $(\mathrm{g}) /$ dry weight $(\mathrm{g})) \times 100$. Hot water extraction (HWE): Dried stevia leaves of $5 \mathrm{~g}$ was dispersed in $100 \mathrm{ml}$ of distilled water equivalent to 20 times of dry weight and mixed at $100^{\circ} \mathrm{C}$ temperature, and the mixture were extracted by centrifuged with $4000 \mathrm{rpm}$ for $20 \mathrm{~min}$ ( $\mathrm{Lim}$ and Oh, 2004). Reflux extraction (RE): Dried stevia leaves of $5 \mathrm{~g}$ were extracted using $50 \mathrm{ml}$ of $100 \% \mathrm{MeOH}$ equivalent to 10 times of dry weight over 3 times for $2 \mathrm{hr}$ using Soxelt extractor (Afandi et al., 2013). High temperature and pressure extraction (HTPE): Dried stevia leaves of $5 \mathrm{~g}$ were added by $100 \mathrm{ml}$ of distilled water equivalent to 20 times of dry weight, and the mixture were extracted by autoclave at $121^{\circ} \mathrm{C}$ for $15 \mathrm{~min}$ (Ko et al., 2015). Ultrasonic extraction (UE): Dried stevia leaves of $0.8 \mathrm{~g}$ were added by $30 \mathrm{ml}$ of solvent (Acetonitrile:Water 7:3) equivalent to 37.5 times of dry weight, and the mixture were extracted by ultrasonic waves at $70^{\circ} \mathrm{C}$ for $15 \mathrm{~min}$ (Ha et al., 2009). Vacuum extraction (VE): Dried stevia leaves of $5 \mathrm{~g}$ were added using $150 \mathrm{ml}$ of distilled water equivalent to 30 times of dry weight, and the mixture were extracted under $0.01 \mathrm{Mpa}$ pressure at $65^{\circ} \mathrm{C}$ for $4 \mathrm{hr}$ (Kim et al., 2010).

\subsection{Determination of Total Phenolic Contents}

Total phenolic contents were analyzed to change by Aronous et al. (2001) method. In a 1.5 $\mathrm{ml}$ Eppendorf tube, $790 \mu \mathrm{l}$ of distilled water and $0.1 \mathrm{ml}$ of sample appropriately diluted, and $50 \mu \mathrm{l}$ of $1 \mathrm{~N}$ Folin-Ciocalteu reagent (Sigma Aldrich, St. Louis, Mo, USA) were mixed. After the reaction for 1 minute exactly, $150 \mu \mathrm{l}$ of $20 \%$ sodium carbonate was added, and the mixture was kept in the dark at room temperature, for $120 \mathrm{~min}$. The absorbance was read at $750 \mathrm{~nm}$ by spectrophotometer (EZ Read 2000, Biochrome, Cambridge, England). The total polyphenol concentration was calculated from a calibration curve, using gallic acid (Sigma 
Aldrich, St. Louis, MO, USA) as a standard. The results expressed as mg gallic acid equivalent (mg GAE) per 100g of dry weight.

\subsection{Determination of Total Flavonoid}

Total flavonoid contents were analyzed to change by Shen et al. (2009) method. Aliquots (0.5 $\mathrm{ml}$ ) of appropriately diluted extracts or standard solutions, $2 \mathrm{ml}$ distilled water were mixed with $0.15 \mathrm{ml} 5 \% \mathrm{NaNO}_{2}$. After the reaction for $5 \mathrm{~min}, 0.15 \mathrm{ml} 10 \% \mathrm{AlCl}_{3} \cdot 6 \mathrm{H}_{2} \mathrm{O}$ solution was added, and the mixture reacted and was left for $5 \mathrm{~min}$, and then $1 \mathrm{~mL} 1 \mathrm{M} \mathrm{NaOH}$ was added. The reaction solution was well mixed, after $15 \mathrm{~min}$. The absorbance was read at $415 \mathrm{~nm}$ by spectrophotometer (EZ Read 2000, Biochrome, Cambridge, England). The total flavonoid concentration was calculated from a calibration curve, using quercetin (Sigma Aldrich, St. Louis, MO, USA) as a standard. The results were expressed as mg quercetin equivalent (mg QE) per 100g of dry weight.

\subsection{DPPH Free Radical Scavenging Activity}

Total antioxidant capacity of extracts (DPPH) was analyzed to use a spectrophotometer by the improved DPPH (1, 1-diphenyl-2-picrylhydrazyl, Sigma Aldrich, St. Louis, MO, USA) method as described (Jeong et al., 2010; Yoon et al., 2016). $200 \mu \mathrm{M}$ DPPH was dissolved in $80 \%$ Methanol. $700 \mu \mathrm{l}$ DPPH was added to $300 \mu \mathrm{l}$ of the extracts and mixed thoroughly. The mixture was kept at room temperature for $30 \mathrm{~min}$ and the absorbance was read at $517 \mathrm{~nm}$ by spectrophotometer (EZ Read 2000, Biochrome, Cambridge, England).

\subsection{ABTS Free Radical Scavenging Activity}

The total antioxidant capacity of extracts (ABTS) was analyzed a spectrophotometer by the improved ABTS (2,2'-azino-bis-3-ethylbenzo-thiazoline-6-sulfonic acid, Sigma Aldrich, St. Louis, MO, USA) method as described (Jeong et al., 2010). ABTS solution (1 ml, absorbance of 0.700 ) was added to $0.1 \mathrm{ml}$ of the extracts and mixed thoroughly. The mixture was kept at $37^{0} \mathrm{C}$ for $20 \mathrm{~min}$ and the absorbance was read at $734 \mathrm{~nm}$ by spectrophotometer (EZ Read 2000, Biochrome, Cambridge, England). Antioxidant activity of DPPH and ABTS was calculated using the formula below and L-ascorbic acid used as control. DPPH and ABTS free radical scavenging activity $(\%)=(1$-sample absorbance/control absorbance $) \times 100$.

\subsection{LC-MS/MS Analysis}

Liquid chromatography-mass spectrometry/ mass spectrometry was performed by coupling a HPLC system (Agilent 1100, Agilent Technologies, CA, USA) to a Qtrap mass spectrometer (Qtrap, AB Sciex CO, CA, USA) equipped with an electrospray ionization (ESI) source. LC separation was performed on an YMC-Pack ODS-AQ Column (150 x 4.6mm x I.D., $5 \mu \mathrm{m})$. The mobile phase consisted of $\mathrm{H}_{2} \mathrm{O}(0.1 \%$ formic acid) and acetonitrile of 50:50 (v/v) up to $2 \mathrm{~min}$, 40:60 till $15 \mathrm{~min}$, delivered at a flow rate of $0.2 \mathrm{ml} / \mathrm{min}$. The column temperature was maintained at $30^{\circ} \mathrm{C}$, and the injection volume was $2 \mu \mathrm{l}$. The standard stevioside and rebaudioside A (Wako pure chemical industries, Ltd, Japan) was used as the internal standard for quantitative analysis. The mass spectrometer was operated under negative ion and selected ion monitoring (SIM) modes. ESI was conducted using a spray voltage of $4.5 \mathrm{kV}$. 
The capillary voltage and the tube lens offset were fixed at -40 and $-130 \mathrm{~V}$, respectively. The heated capillary temperature was fixed at $400^{\circ} \mathrm{C}$.

\subsection{Statistical Analysis}

The data were analyzed using one-way analysis of variance (ANOVA) by SPSS Statistics 21 program. The statistical assessments of the differences between mean values were compared using Duncan's multiple range test (DMRT) at $p=0.05$.

\section{Results and Discussion}

\subsection{Analysis of Sweetness Components According to Extraction Methods}

Natural sweetness components like rebaudioside A and stevioside in stevia were extracted by 5 methods such as HWE, RE, HTPE, UE and VE to select the method with high extraction yield. The result showed that the extraction yield was no difference with treatments except for VE treatment, and the content of sweetness was the highest in HTPE, followed by VE, RE, HWE, and UE, in that order (Table 1; Fig. 1). Periche et al. (2015) reported that steviol glycosides and antioxidants were negatively correlated; therefore, there is no single treatment suitable for obtaining the highest yield in both groups of compounds simultaneously. The greatest yield of steviol glycosides was obtained with microwave energy or ultrasonic treatment, and the conventional method (hot water) was the most suitable for antioxidant extraction. Nonetheless, in this study, steviol glycosides content was the highest in HTPE and the lowest in UE and HWE (Fig. 1). It seems that HTPE had a high pressure as well as high temperature in this study. Also, VE was the highest in the content of antioxidants as much as HTPE, but in extraction yield VE was the lower compared to HTPE (Fig. 2). Kim et al. (2010) reported that VE is efficient for the extraction of antioxidants in stevia, although the content of steviol glycosides are not represented. Therefore, despite VE method was suitable for antioxidants extraction, it had some weakness of low extraction efficiency of sweetness components and it requires much equipment. In this study, the content of antioxidants by UE methods is agreement with report of Periche et al. (2015), but the content of steviol glycoside was different in this study (Fig. 1).

Table 1. Comparison of extraction yield in extracts of stevia leaves according to extraction methods.

\begin{tabular}{cc}
\hline Extraction methods & Extraction yield (\%) \\
\hline Hot water extraction & $51.0 \mathrm{a}^{\mathrm{z}}$ \\
Reflux extraction & $47.6 \mathrm{a}$ \\
High Temperature and Pressure extraction & $45.1 \mathrm{a}$ \\
Ultrasonic extraction & $48.8 \mathrm{a}$ \\
Vacuum extraction & $18.5 \mathrm{~b}$ \\
\hline
\end{tabular}

\footnotetext{
${ }^{\mathrm{z}}$ Mean separation within columns by Duncan's multiple range at $p<0.05$.
} 


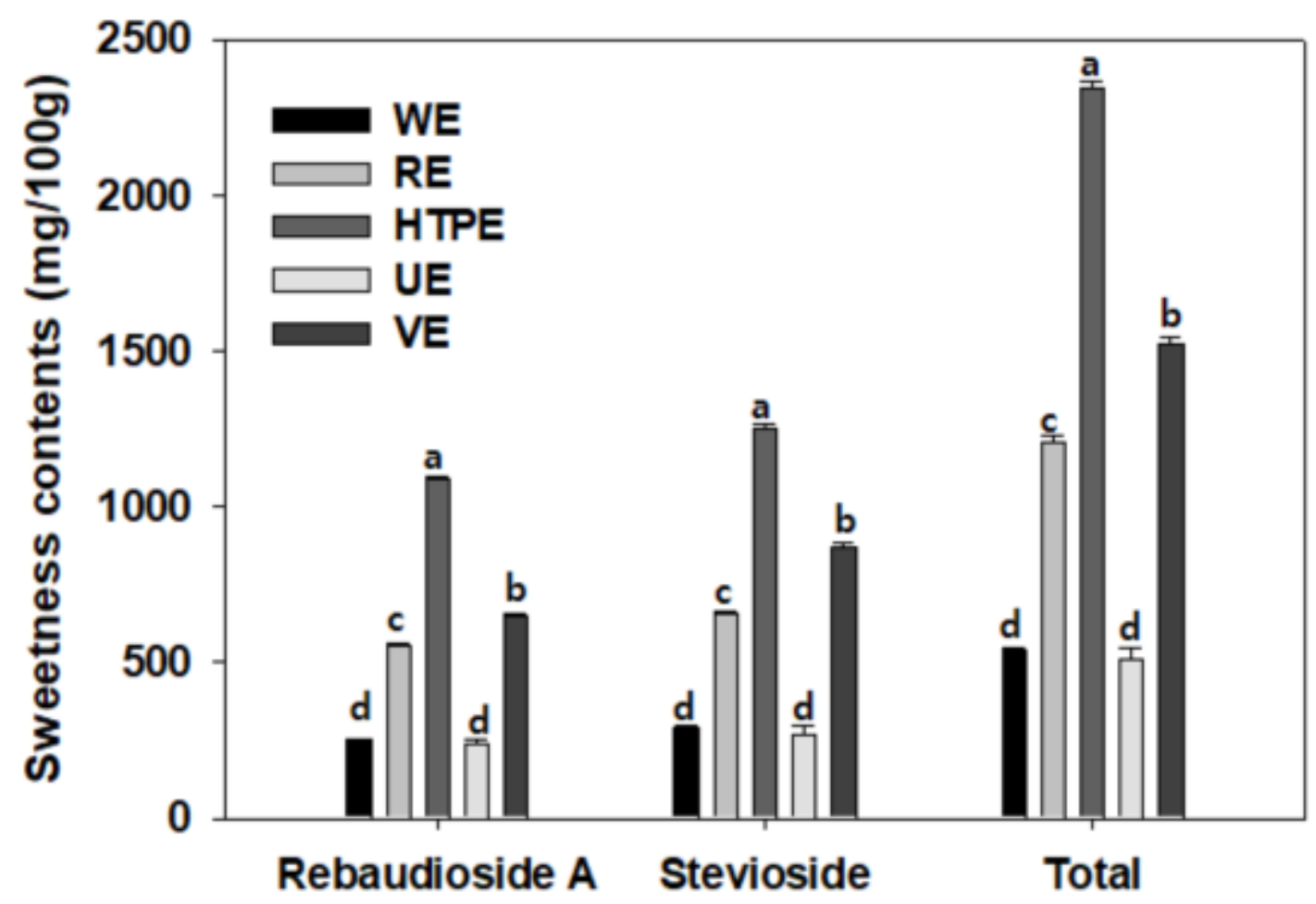

Fig. 1. Comparison of sweetness components in stevia leaves according to extraction methods. Total shows the sum of rebaudioside A and stevioside. WE: Hot water extraction, RE: Reflux extraction, HTPE: High temperature and pressure extraction, UE: Ultrasonic extraction, VE: Vacuum extraction. Data represent the means $\pm S E(n=3)$. Different letters are significantly different at $p<0.05$ by Duncan's Multiple Range Test (DMRT) 


\section{Mll Macrothink $\Lambda$ Institutem"}

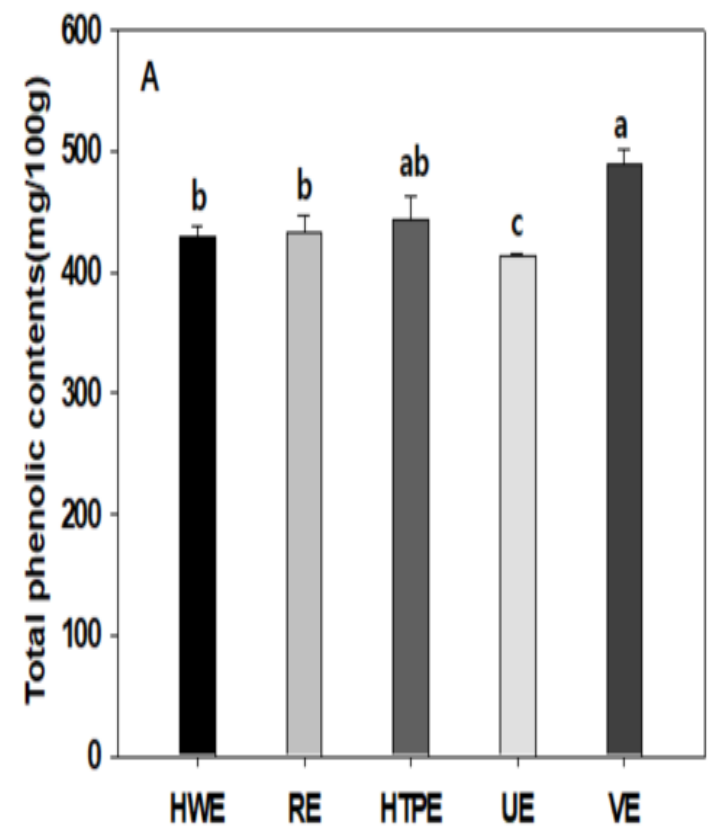

Journal of Agricultural Studies

ISSN 2166-0379 2019, Vol. 7, No. 1

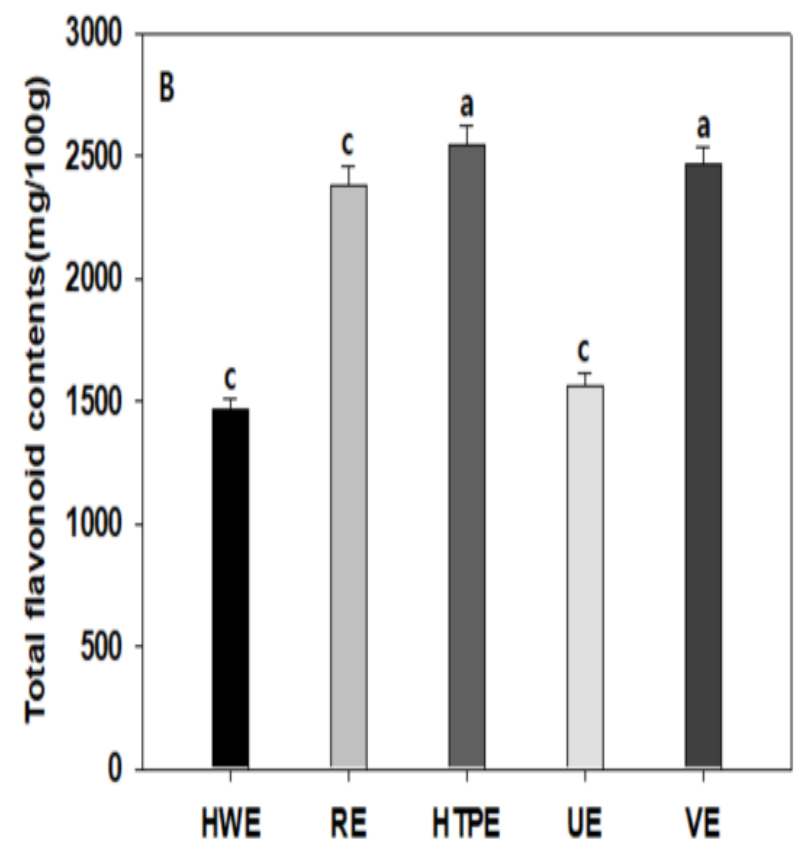

Fig. 2. Total phenolic contents (A) and total flavonoid contents (B) in stevia leaves according to extraction methods. HWE: Hot water extraction, RE: Reflux extraction, HTPE: Pressure heating water extraction, UE: Ultrasonic extraction, VE: Vacuum extraction. Data represent the means $\pm \mathrm{SE}(\mathrm{n}=3)$. Different letters are significantly different at $p<0.05$ by Duncan's Multiple Range Test (DMRT)

Therefore, it seems that HTPE is the most suitable method because this extraction method has the highest content of rebaudioside A, stevioside, extraction yield and antioxidants than other extraction methods.

\subsection{Extraction Yield According to Harvest Times and Parts}

The extraction yield in stevia leaves according to harvest times was the highest in October, followed by September, and May, in such order. The other harvest times, Apr, June, July and August, were the lowest and these periods have no difference among them. There was no difference between July and September, regarding the extraction yield in stevia stem according to harvest times (Table 2). Also, the leaves in stevia was higher in extraction yield than that of the stem. 


\section{Macrothink}

Journal of Agricultural Studies

ISSN 2166-0379

2019, Vol. 7, No. 1

Table 2. Comparison of extraction yield in extracts of stevia leaves according to harvest times

\begin{tabular}{ccc}
\hline Harvest times & \multicolumn{3}{c}{ Extraction yield (\%) } \\
\cline { 2 - 3 } & Leaves & Stem \\
\hline Apr. & $36.2 \mathrm{c}^{\mathrm{z}}$ & - \\
May & $39.5 \mathrm{bc}$ & - \\
Jun. & $36.8 \mathrm{c}$ & - \\
Jul. & $33.6 \mathrm{c}$ & $18.5^{\mathrm{ns}}$ \\
Aug. & $35.6 \mathrm{c}$ & - \\
Sep. & $45.1 \mathrm{~b}$ & 21.2 \\
Oct. & $52.6 \mathrm{a}$ & - \\
\hline
\end{tabular}

${ }^{\mathrm{z}}$ Mean separation within columns by Duncan's multiple range at $p<0.05$.

${ }^{\text {ns }}$ No significance at 0.05 level

3.3 Analysis of Sweetness Components and Antioxidants Activity According to Harvest Times and Parts

Steviol glycosides of rebaudioside A and stevioside content according to harvest times in stevia leaves was increased from April to October as rising temperature, and decreased since October (Fig. 3). Wu et al. (2012) reported that contents of rebaudioside A and stevioside was higher in leaves harvested at 95days than in leaves harvested at 65 85days and 105 days after planting. These results have the same tendency with this study. The result showed that it is higher in leaves harvested in late cultivation than in leaves harvested during early cultivation. Nevertheless, it had the tendency to decrease in August. Consequently, the contents of rebaudioside $\mathrm{A}$ and stevioside were decreased by extreme high temperature in that season. Lim and Oh (2004) observed that the content of steviol glycoside decreased from the highest peak season of August, but it is the difference in this study. It seems that steviol glycoside content was derived from the different extraction methods such as HTPE and weather condition cultivated in stevia such as the hottest of August in Korea as mentioned above. Contents of rebaudioside A and stevioside in stevia were higher in leaves than in stem (Fig. 4). This was consistent with the general opinion that there are abundant natural sweetness components contained in stevia leaves (Afandi et al., 2013; Periche et al., 2015). 


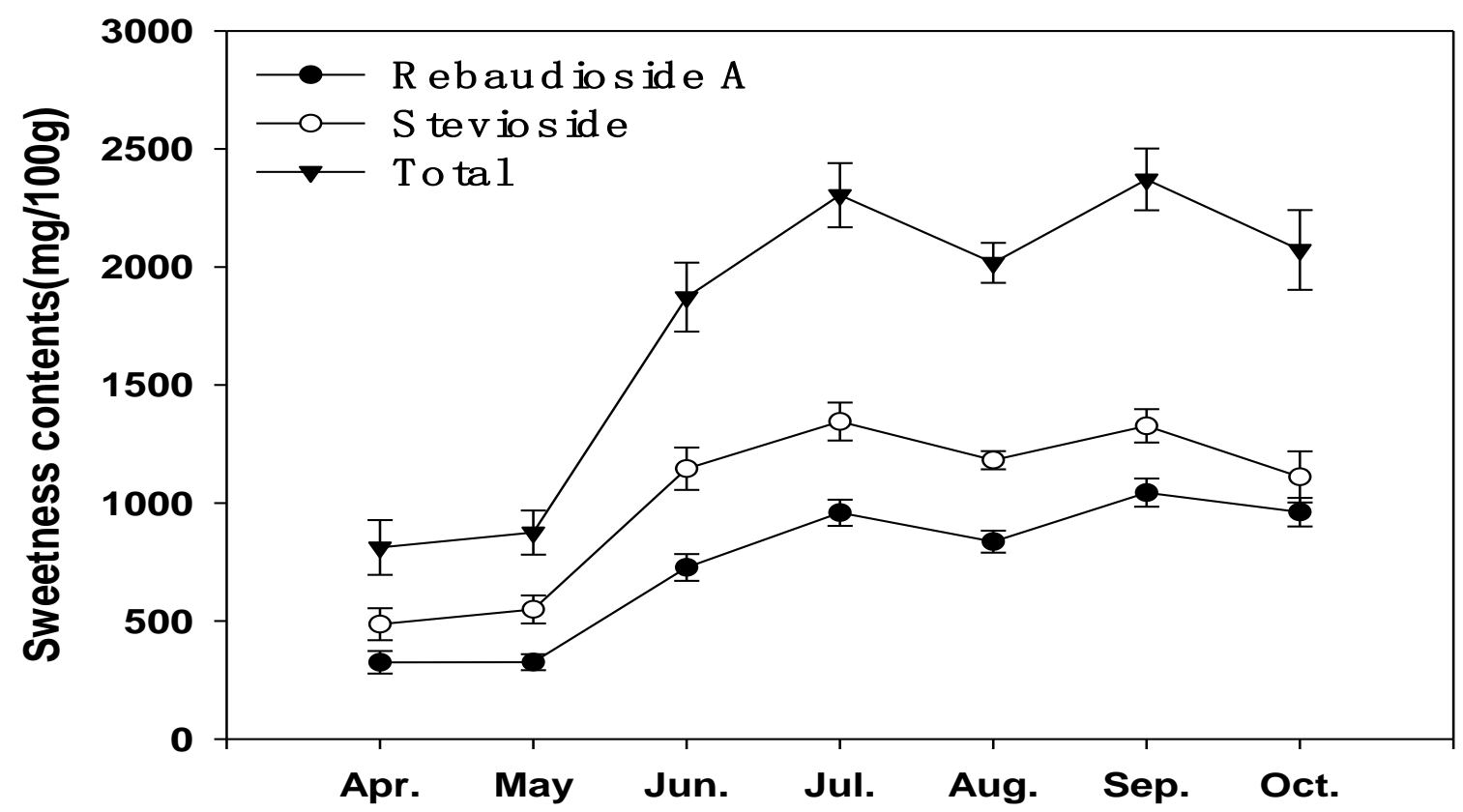

Fig. 3. Seasonal change of sweetness components in stevia leaves according to harvests time. Total shows the sum of rebaudioside A and stevioside. Data represent the means $\pm S E(n=3)$

Table 3. Comparison of antioxidant contents and activity in pressure heating water extraction of stevia leaves according to harvest times

\begin{tabular}{cccccc}
\hline \multirow{2}{*}{$\begin{array}{c}\text { Harvest } \\
\text { times }\end{array}$} & $\begin{array}{c}\text { Total phenolic } \\
\text { contents }\end{array}$ & $\begin{array}{c}\text { Total flavonoid } \\
\text { contents }\end{array}$ & & DPPH & ABTS \\
\cline { 2 - 3 } \cline { 5 - 6 } \cline { 5 - 6 } & \multicolumn{2}{c}{$\mathrm{mg} \cdot 100 \mathrm{~g}^{-1}$} & & \multicolumn{2}{c}{$\%$} \\
\hline Apr. & $443.2 \mathrm{ab}^{\mathrm{z}}$ & $2468.4 \mathrm{a}$ & & $36.0 \mathrm{a}$ & $92.9 \mathrm{a}$ \\
May & $477.7 \mathrm{a}$ & $2468.4 \mathrm{a}$ & & $34.9 \mathrm{a}$ & $81.1 \mathrm{a}$ \\
Jun. & $463.0 \mathrm{ab}$ & $2488.0 \mathrm{a}$ & & $37.3 \mathrm{a}$ & $90.4 \mathrm{a}$ \\
Jul. & $427.0 \mathrm{~b}$ & $2464.0 \mathrm{a}$ & & $29.8 \mathrm{ab}$ & $86.9 \mathrm{a}$ \\
Aug. & $482.1 \mathrm{a}$ & $2512.0 \mathrm{a}$ & & $34.6 \mathrm{a}$ & $88.3 \mathrm{a}$ \\
Sep. & $447.7 \mathrm{ab}$ & $2536.0 \mathrm{a}$ & & $20.8 \mathrm{~b}$ & $86.3 \mathrm{a}$ \\
Oct. & $448.3 \mathrm{ab}$ & $2523.4 \mathrm{a}$ & & $37.2 \mathrm{a}$ & $90.0 \mathrm{a}$ \\
\hline
\end{tabular}

${ }^{\mathrm{z}}$ Mean separation within columns by Duncan's multiple range at $p<0.05$. 

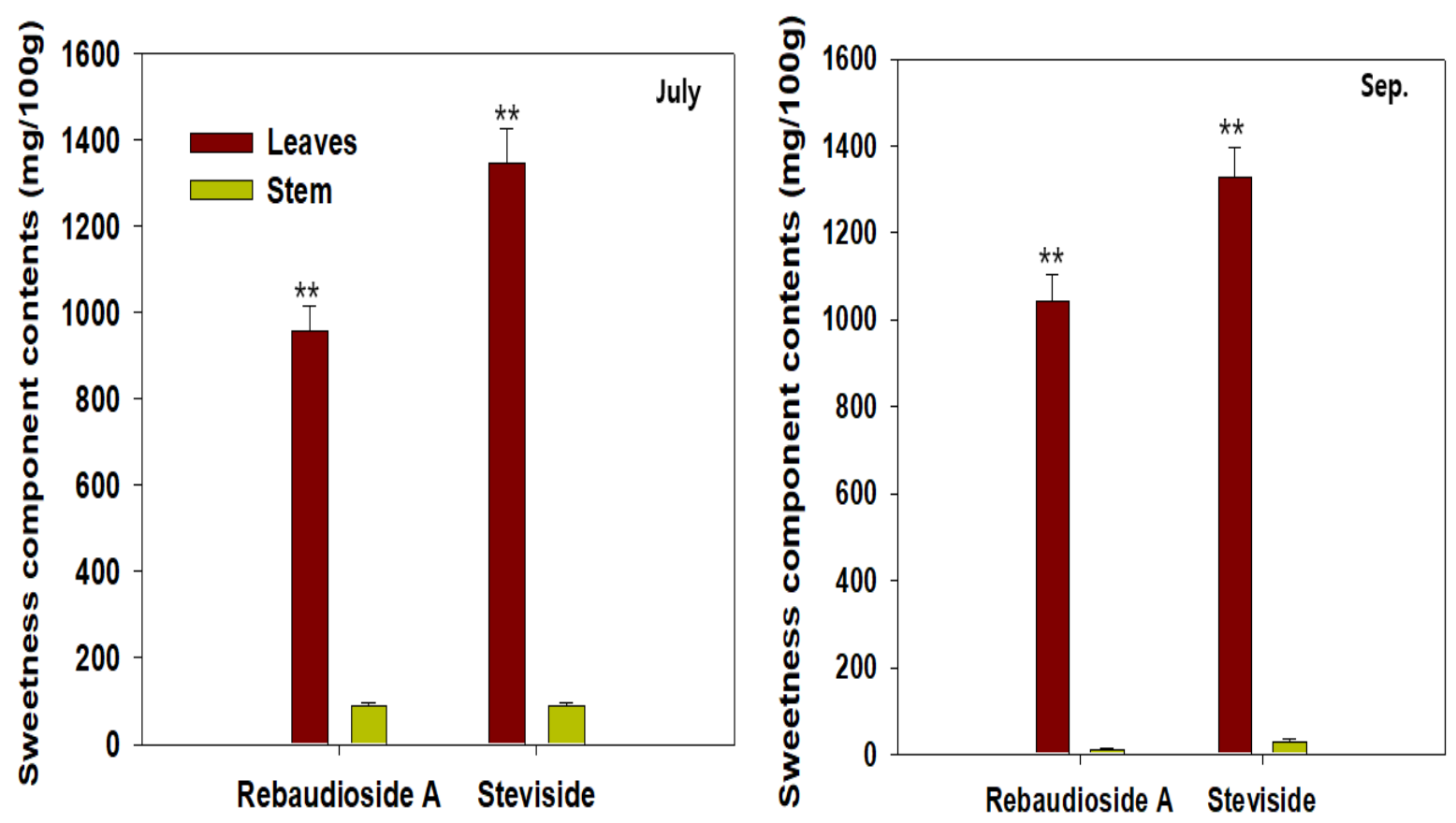

Fig. 4. Comparison of sweetness components in stevia leaves and stem in July and September.

Mean values \pm SE from triplicate separated experiments are shown. Statistical difference show significantly different at $* p<0.05$ and $* * p<0.01$ by t-test

The total phenolic compound content in leaves was the highest in August and May, but flavonoid content was not different in harvest times. All harvest times of the DPPH activity in stevia leaves was represented with low activity under 40\%, and ABTS activity was not different during harvest times (Table 3). Also, stems, the total phenolic compound was not different with harvest times. Although flavonoid content was higher in July than in September, the content was very low compared to leaves. The DPPH activity by harvest times in stevia stem was higher in September than in July, and ABTS activity was not different in harvest times (Table 4). There were few researches on antioxidant and activity according to harvest times. Although Lim and Oh (2004) observed contents of steviol glycoside according to harvest times, they were not analyzed to antioxidants.

Table 4. Comparison of antioxidant contents and activity in extracts of stevia stem harvested at different time

\begin{tabular}{cccccc}
\hline \multirow{2}{*}{$\begin{array}{c}\text { Harvest } \\
\text { times }\end{array}$} & $\begin{array}{c}\text { Total phenolic } \\
\text { contents }\end{array}$ & $\begin{array}{c}\text { Total flavonoid } \\
\text { contents }\end{array}$ & & DPPH & ABTS \\
\cline { 2 - 3 } \cline { 5 - 6 } & \multicolumn{2}{c}{$\mathrm{mg} \cdot 100 \mathrm{~g}^{-1}$} & & 20.5 & \\
\hline Jul. & $409.5^{\mathrm{ns}}$ & $2,355.6^{* * \mathrm{z}}$ & & $\%$ & \\
Sep. & 379.3 & $1,322.4$ & & 68.5 & $95.2^{\text {ns }}$ \\
\hline
\end{tabular}

\footnotetext{
${ }^{\mathrm{ns}}$ Not significant.

${ }^{\mathrm{z}}$ Stars show significantly different at $p<0.05$ and $p<0.01$ by t-test.
} 
In conclusion, stevia leaves are better than stevia stems regarding the use of rebaudioside A and stevioside as natural sweeteners. Also, it was confirmed that the stevia leaves of July, September and October, excluding the high temperature period of August, had superior in quality and quantity.

\section{Acknowledgements}

This research was supported by grant No. PJ0138342018 from the Agricultural R\&D, Rural Development Administration, Republic of Korea.

\section{Reference}

Afandi, A., Sarijan, S., \& Shaha, R. K. (2013). Optimization of rebaudioside A extraction from Stevia rebaudiana (Bertoni) and quantification by high performance liquid chromatography analysis. Journal of Tropical Resources and Sustainable Science, 1, 62-70.

Arnous, A., Makris, D. P., \& Kefalas, P. (2001). Effect of principal polyphenolic components in relation to antioxidant characteristics of aged red wines. Journal of Agricultural and Food Chemistry, 49, 5736-5742. https://doi.org/10.1021/jf010827s

Choi, Y. S., Jung, M. H., Soh, W. Y., Han, K. S., \& Yeo, U. D. (2011). Changes of antioxidant enzymes in stevia plants under clinorotation, shaking, and low temperature stresses. Korean Journal of Plant Resources, 24, 343-350. https://doi.org/10.1021/jf010827s

Dyrskog, S. E., Jeppersen, P. B., Colombo, M., Abudula, R., \& Hermansen, K, (2005). Preventive effects of a soy-based diet supplemented with stevioside on the development of the metabolic syndrome and type 2 diabetes in Zucker diabetic fatty rats. Metabolism, 54, 1181-1188. https://doi.org/10.1016/j.metabol.2005.03.026

Esmat, Abou-Arab A., Azza, Abou-Arab, A., \& Ferial, Abu-Salem, M. (2010). Physico-chemical assessment of natural sweeteners steviosides produced from Stevia rebaudiana bertoni plant. African Journal of Food Science, 4, 269-281.

Ha, J. H., Jeong, H. S., Jeong, M. H., Kim, S. S., Jun, L., Nam, J. H., ... Lee, H. Y. (2009). Comparison of anticancer activities of ultrasonification extraction of callus and roots from Rhodiola sachalinensis A. Bor. Korean Journal of Food Science and Technology, 41, 552-559.

Hwang, E. J., Yoo, J. H., Shin, J. Y., Bae, M. J., \& Jo, S. I. (2016). Association of sugar-sweetened beverages consumption and hypertension in Korean adults: Korean national health and nutrition examination survey 2012-2013Korean Journal of Family Practice, 6, 446-451. https://doi.org/10.21215/kjfp.2016.6.5.446

Jeong, J. H., Jung, H. N., Lee, S. R., Lee, H. J., Hwang, K. T., \& Kim, T. Y. (2010). Anti-oxidant, anti-proliferative and anti-inflammatory activities of the extracts from black raspberry fruits and wine. Food Chemistry, 123, 338-344.

https://doi.org/10.1016/j.foodchem.2010.04.040 
Kim, H. A., \& Lee, K. H. (2012). Quality characteristics of yanggeng made with various sweeteners. Journal of the East Asian Society of Dietary Life, 22, 818-825.

Kim, J. H., Sung, N. Y., Kwon, S. K., Jung, P M., \& Choi, J. I. (2010). Antioxidant activity of stevia leaf extracts prepared by various extraction methods. Journal of the Korean Society of Food Science and Nutrition, 39, 313-318. https://doi.org/10.3746/jkfn.2010.39.2.313

Kim, W. W., Kim, H. S., Lee, B. C., Jin, C. W., \& Cho, D. H. (2009). Antioxidative and cytotoxicity in human cancer cell lines of the extracts of Stevia rebaudiana Bertoni. The Korean Society of Medicinal Crop Science (supplement I), Geumsan, Korea, May 7 8, pp. 367-368.

Ko, G. A., Son, M., Kang, H. R., Lim, J. H., Im, G. H., \& Cho, S. M. (2015). Antioxidant activities of blueberry hot water extracts with different extraction condition. Korean Journal of Food Preservation, 22, 428-436. https://doi.org/10.11002/kjfp.2015.22.3.428

Lee, K. J., \& Kim, M. R. (2004). Quality evaluation of pumpkin jam replaced sucrose with sugar alcohols during storage. Journal of the East Asian Society of Dietary Life, 14, 123-130. Lim, H. J., \& Oh, S. L. (2004). Quality of extracts from domestic stevia (Stevia rebaudiana Beroni) leaves with harvest time. Korean Journal of Food Preservation, 11, 491-495.

Na, Y. M., Lee, Y. J., \& Chun, S. S. (2012). Quality characteristics of tomato jam added with fructose-oligosaccharide. Journal of the Korean Society of Food Science and Nutrition, 41, 227-232. https://doi.org/10.3746/jkfn.2012.41.2.227

Park, J. E. (2007). Effect of Stevia rebaudiana Bertoni extract supplementation on antiobesity and glycemic control. CBNU, Cheongju, Korea, pp. 1-54. Reference to a Master thesis

Park, J. E., Kee, H. J., \& Cha, Y. S. (2010). Effect of Stevia rebaudiana Bertoni leaf extract on antiobesity in C57BL/6J mice. Korean Journal of Food Science and Technology, 42, 586-592.

Periche, A., Castello, M. L., Heredia, A., \& Escriche, I. (2015). Influence of extraction methods on the yield of steviol glycosides and antioxidants in Stevia rebaudiana extracts. Plant Foods for Human Nutrition, 70, 119-127. https://doi.org/10.1007/s11130-015-0475-8

Shen, Y., Jin, L., Xiao, P., Lu, Y., \& Bao, J. (2009). Total phenolics, flavonoids, antioxidant capacity in rice grain and their relations to grain color, size and weight. Journal of Cereal Science, 49, 106-111. https://doi.org/10.1016/j.jcs.2008.07.010

Tadhani, M. B., Patel, V. H., \& Subhashm R, (2007). In vitro antioxidant activities of Stevia rebaudiana leaves and callus. Journal of Food Composition and Analysis. 20, 323-329. https://doi.org/10.1016/j.jfca.2006.08.004

Tomita, T., Sato, N., Arai, T., Shiraishi, H., Sato, M., Takeuchi, M., \& Kamio, Y. (1997). Bacterial activity of a fermented hot-water extract from Stevia rebaudiana Bertoni towards enterohemorrhagic Escherichia coli $\mathrm{O} 157: \mathrm{H} 7$ and other food-borne pathogenic bacteria. $\begin{array}{llll}\text { Microbiology and Immunology, } & 41, & 1005-1009 .\end{array}$ https://doi.org/10.1111/j.1348-0421.1997.tb01961.x 


\section{Macrothink}

Journal of Agricultural Studies

ISSN 2166-0379 2019, Vol. 7, No. 1

Wu, J., Yang, J., Nakagoshi, N., Lu, X., \& Xu, H. (2012). The Effect of different harvest date on the quality and yield of Stevia rebaudiana Bertoni Adv Mater doi:10.4028/www.scientific.net/ AMR. 524-527.2109.

Yamamoto, N., Mizue, S., Sano, K., Takano, N., Miyamoto, A., Ueno, Y., ... Mochizuki, S. (2001). Characterization of food composition and functionality of herbs cultivated in Oita. Report 36, Oita, Japan, pp. 144-149.

Yoon, K. K., Moon, K. G., Kim, S. U., Um, I. S., Cho, Y. S., Kim, Y. G., \& Rho, I. R. (2016). Analysis of growth and antioxidant compounds in deodeok in response to mulching materials. The Korean Society of Medicinal Crop Science, 24, 183-190. https://doi.org/10.7783/KJMCS.2016.24.3.183

\section{Copyright Disclaimer}

Copyright for this article is retained by the author(s), with first publication rights granted to the journal.

This is an open-access article distributed under the terms and conditions of the Creative Commons Attribution license (http://creativecommons.org/licenses/by/4.0/). 